\title{
MicroRNAs as Clinical Biomarkers and Therapeutic Tools in Perioperative Medicine
}

\author{
Simone Kreth, MD, PhD, ${ }^{*}+$ Max Hübner, MD, ${ }^{*} \dagger$ and Ludwig Christian Hinske, MD*
}

\begin{abstract}
Over the past decade, evolutionarily conserved, noncoding small RNAs-so-called microRNAs (miRNAs) - have emerged as important regulators of virtually all cellular processes. miRNAs influence gene expression by binding to the $3^{\prime}$-untranslated region of protein-coding RNA, leading to its degradation and translational repression. In medicine, miRNAs have been revealed as novel, highly promising biomarkers and as attractive tools and targets for novel therapeutic approaches. miRNAs are currently entering the field of perioperative medicine, and they may open up new perspectives in anesthesia, critical care, and pain medicine. In this review, we provide an overview of the biology of miRNAs and their potential role in human disease. We highlight current paradigms of miRNA-mediated effects in perioperative medicine and provide a survey of miRNA biomarkers in the field known so far. Finally, we provide a perspective on miRNA-based therapeutic opportunities and perspectives. (Anesth Analg 2018;126:670-81)
\end{abstract}

T The idea that small noncoding RNAs might be able to break the paradigm of a linear correlation between mRNA and protein expression first came up almost 25 years ago. In 1993, Lee et $\mathrm{al}^{1}$ found that, in Caenorhabditis elegans, the gene lin-4 did not encode a protein, but rather a small RNA that is able to reduce protein levels of lin-14. Almost 7 years later, Bartel et al were able to identify the similarly acting, small noncoding RNA let-7 in multiple species, including Homo sapiens, leading to speculation that probably more molecules of a similar kind might exist. ${ }^{2}$ This assumption proved true within a year, when Lagos-Quintana et $\mathrm{al}^{3}$ successfully cloned several new so-called microRNAs (miRNAs). The major properties of miRNAs are that they are processed from a precursor that contains a hairpin structure, that their active form is a single-stranded RNA molecule of $\sim 22$ nucleotides in length, and that they seem to primarily bind to the 3'-untranslated region (UTR) of certain mRNAs, thereby negatively impacting protein levels.

To date, 1881 human miRNA sequences ${ }^{4}$ have been identified, and knowledge about miRNA function and their importance in the regulation in virtually all relevant biologic processes has largely evolved. It has become increasingly clear that miRNAs are major elements in fine-tuning the expression of more than $30 \%$ of all protein-coding genes within the human organism and that these small molecules play a critical role not only in homeostasis but also in the development and maintenance of numerous pathological processes.

From the *Department of Anesthesiology, and †Walter-Brendel-Centre of Experimental Medicine, University of Munich (LMU), Munich, Germany.

Accepted for publication July 25, 2017.

Funding: None.

The authors declare no conflicts of interest.

Reprints will not be available from the authors.

Address correspondence to Simone Kreth, MD, PhD, Department of Anesthesiology, University of Munich (LMU), Munich, Germany. Address e-mail to simone.kreth@med.uni-muenchen.de.

Copyright (C) 2017 The Author(s). Published by Wolters Kluwer Health, Inc on behalf of the International Anesthesia Research Society. This is an openaccess article distributed under the terms of the Creative Commons Attribution-Non Commercial-No Derivatives License 4.0 (CCBY-NC-ND), where it is permissible to download and share the work provided it is properly cited. The work cannot be changed in any way or used commercially without permission from the journal.

DOI: 10.1213/ANE.0000000000002444

\section{MIRNA BIOGENESIS AND TARGET INTERACTION}

Genes coding for the miRNA class of molecules are heterogeneously located within the human genome: whereas about half of human miRNAs genes are intergenic, that is, found in distant locations from currently annotated genes, the other half of currently known miRNA genes are intragenic, that is, located within protein-coding genes. The expression of miRNAs is tightly regulated by the same mechanisms controlling gene expression generally. While intergenic miRNAs possess own promoters, intragenic miRNAs are usually cotranscribed together with their host gene and then further processed to mature miRNAs. ${ }^{5}$ Promoter activities are determined by binding of transcription factors, silencers, and DNA methylation processes. Consequently, the expression of miRNA is strongly influenced by environmental factors and external stimuli, such as inflammation, hypoxia, or treatment with drugs. Also, diverse classes of RNAs, so-called ceRNAs (competing RNAs, eg, pseudogenes, long noncoding RNAs, circular RNAs, and also messenger RNAs) can reduce the influence of miRNAs by competing for binding sites or by acting as miRNAabsorbing "sponges," thus reducing the levels of available miRNAs. ${ }^{6}$

miRNAs are transcribed by the polymerase Pol II (Figure 1A), ${ }^{7}$ and the resulting transcriptional product, called primary miRNA (pri-miRNA), can vary greatly in length, up to several thousands of nucleotides. This pri-miRNA forms a hairpin loop structure that undergoes further processing in the so-called microprocessor, a protein complex including the RNA-binding enzyme DGCR8 and the RNAse III Drosha. ${ }^{8}$ Drosha cuts the double-stranded end, leaving a 70 nucleotide long hairpin precursor miRNA (pre-miRNA). ${ }^{9}$ As is typical for RNAse III cleavage, the pre-miRNA contains a 2 nucleotide 5 '-end overhang that is recognized by Exportin 5 , which is necessary for transport into the cytoplasm. ${ }^{10}$ In a second processing step, a protein complex including the RNA recognizing protein TAR RNA binding protein and another enzyme of the RNAse III family, Dicer, cuts out the hairpin loop structure, leaving the mature miRNA:miRNA* double strand. ${ }^{11}$ Usually, 1 of the 2 strands is degraded, whereas the other is incorporated into the so-called RNAinduced silencing complex. ${ }^{12}$ The miRNA incorporated in the 
Figure 1. A, miRNA biosynthesis pathway. miRNA genes are transcribed by $\mathrm{Pol} 2 / 3$ from the DNA (primary miRNA transcript) and cleaved through the Drosha/DGCR8 complex (precursor miRNA). After export from the nucleus via Exportin-5/ RAN-GTP, Dicer in conjunction with TAR RNA binding protein do the final processing, leaving the mature miRNA transcripts. $B$, miRNA transcript recognition and targeting. After processing, the miRNA is loaded into the RNA-induced silencing complex (RISC) that consists of Ago and Ago-interacting proteins, such as Dcp and Gw182. The miRNA then recognizes its target message through base-pairing to the target's 3'-untranslated region. The most important region for this interaction in animals is the seed region (miRNA sequence in red). Imperfect seed-pairing can be compensated for by high degree of complementarity to the 3 '-end of the miRNA.
A

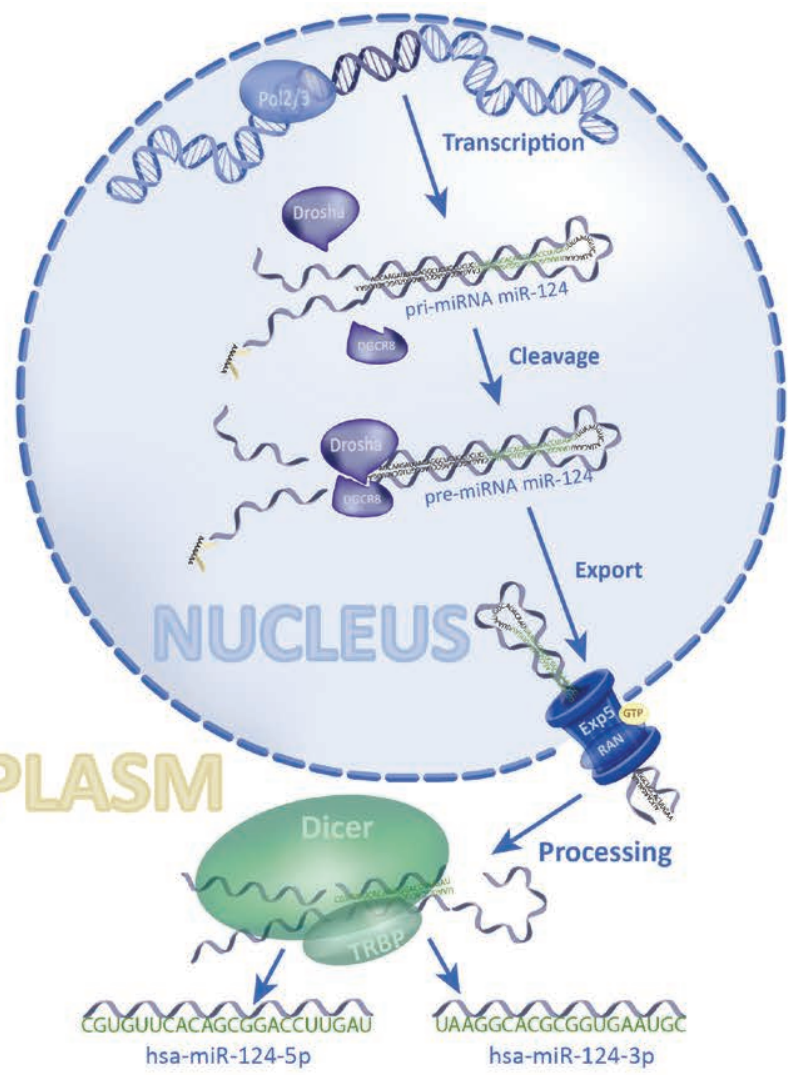

B

miRNA (hsa-miR-124-3p)

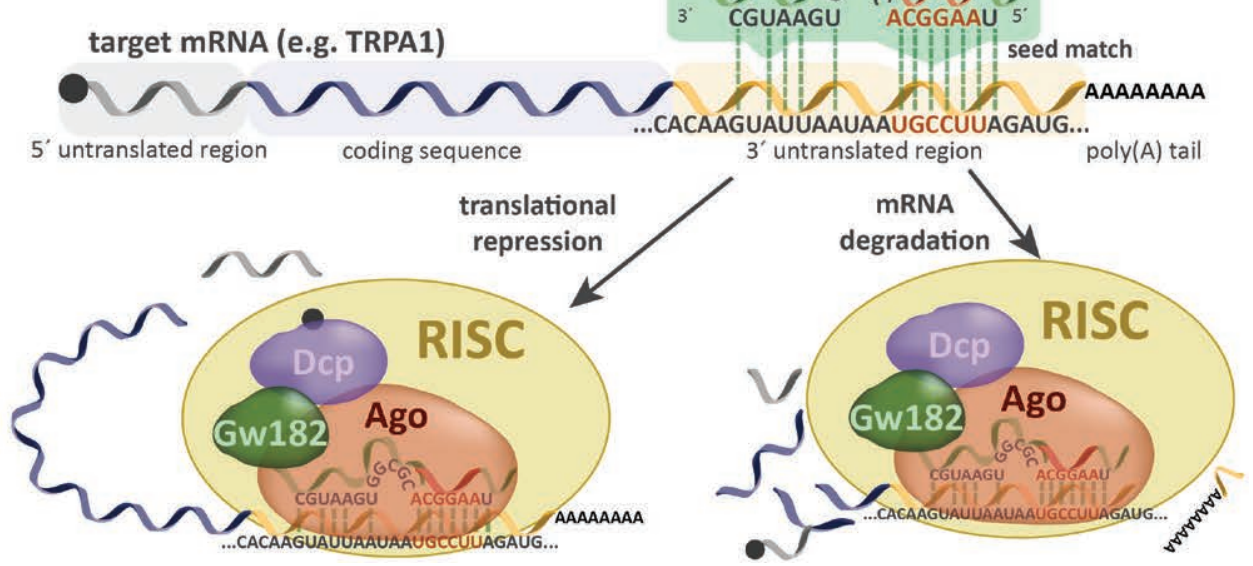

RNA-induced silencing complex recognizes its target mRNA through Watson-Crick complementarity of its 5'-end to the 3'-UTR of its target (Figure 1B). Whereas in plants miRNAs seem to nearly perfectly match the target sequence, this is not true in mammals, where imperfect pairing is predominant and near-perfect complementarity is only required for the "seed-region" of the mature miRNA (nucleotides 2-7). After recognition, miRNAs regulate target mRNAs through either translational repression or mRNA destabilization or a combination of both mechanisms. Recent research has indicated that mRNA degradation explains the majority of miRNAmediated repression, while translational repression accounts for roughly $10 \%$ to $25 \%$ of the overall repression. ${ }^{13,14}$ In most cases, miRNA-induced changes in gene expression are subtle with net repressions in the range of 2- to 5-fold, and biological effects are achieved by high redundancy: each miRNA can regulate multiple target genes, while one protein-coding mRNA can be targeted by multiple miRNAs. Usually, miRNAs act in networks, that is, one single miRNA regulates not only one mRNA but also further transcripts within the target interactome. Also, as one single miRNA is merely sufficient to influence entire signaling pathways, it is a frequently occurring phenomenon that several miRNAs act together in a similar direction. This situation is further complicated by the existence of indirect miRNA-mRNA interactions: for example, by targeting transcription factors, suppressor proteins, or 
enzymes that catalyze DNA methylation, miRNAs can, without evident binding sites within the 3'-UTRs of the regulated genes, unexpectedly impact gene expression. ${ }^{15}$

In this highly complex scenario, various in silico prediction algorithms have been developed during the last decade to identify potential direct and indirect miRNA-target interactions and to allow for subsequent experimental validation and characterization. ${ }^{16}$

\section{MIRNAS IN HUMAN DISEASE}

It is well known that the miRNA repertoire expressed by each cell type is highly specific. Likewise, miRNA expression patterns of different tissues are characteristic and contribute to the shaping of specific tissue features and functions. Some miRNAs are even exclusively expressed in certain tissues or cell types. It thus is not surprising that also for a wide spectrum of human diseases-ranging from cancer, hematologic, cardiovascular, and neurologic diseases to pathologic conditions caused by dysfunctions of the immune system-specific miRNA expression patterns could be identified. ${ }^{17-20}$ Mostly, the assignment of specific miRNAs to certain diseases is only based on correlative analyses; however, for some of these miRNAs, causal links to pathogenesis have been revealed: for example, miR-21 has been shown to act as a proto-oncogene in multiple cancers including colorectal adenocarcinoma and breast cancer, ${ }^{21}$ or miR-146a, which acts as inhibitor of inflammatory processes by dampening nuclear factor- $\kappa \mathrm{B}(\mathrm{NF}-\kappa \mathrm{B})$ signaling and thus is frequently suppressed in inflammatory diseases. ${ }^{22}$

miRNAs not only influence gene expression within their parental cells, they also act as signaling molecules promoting intercellular communication. Recent research discovered that miRNAs can be packaged into exosomes or microvesicles and subsequently are released from cells into the surrounding tissue or into the circulation. Other cells can take up these secreted miRNAs, which then establish their regulative activity in the new cellular surrounding. ${ }^{23-25}$ Unlike other extracellular RNA molecules, the membrane-enclosed or lipid-bound extracellular miRNAs are remarkably stable and can be detected in virtually all body fluids, including blood, saliva, bronchial secretions, urine, liquor, and breast milk. ${ }^{26}$

Due to these unique features-disease specificity, high stability, and accessibility-miRNAs have already gained importance as useful clinical biomarkers for diagnosis and prognosis of specific diseases and to monitor treatment responses. Accordingly, during the last decade, strong efforts have been made in almost all clinical fields to identify and to validate single or sets of miRNAs as convincing biomarkers. ${ }^{27,28}$

Due to their broad regulative capabilities, miRNAs also bear a high potential as therapeutic targets ${ }^{29}$ - at least in diseases in which a clear causal link between the pathologic state and the altered expression of specific miRNAs has been found. In the last few years, several formulations of miRNA mimetics and inhibitors targeting specific pathology-driving genes have been developed and administered to patients within the framework of clinical studies, which will be discussed below. So far, these highly interesting approaches are still preliminary and need extensive improvement. Nonetheless, the field of miRNA therapies has made a huge leap forward.

\section{MIRNAS IN CRITICAL CARE MEDICINE}

In critical care medicine, there is still an urgent need for valid biomarkers that enable an early and precise detection of life-threatening disorders such as sepsis, acute lung injury (ALI), and the frequently associated failure of organs. In this regard, miRNAs have increasingly gained attention during the last years, and a remarkable number of single miRNAs, or of miRNA sets as new biomarkers, have been proposed. The implementation of these biomarkers into the clinical routines is an ongoing task and some hurdles still have to be taken. Also, a multitude of both in vitro and animal studies aiming at the elucidation of specific miRNA effects and the underlying molecular mechanisms have been published.

Herein, we will provide a short survey of the current status quo in sepsis, ALI, and acute organ dysfunction.

\section{SEPSIS}

It is well established that miRNAs are potent regulators of both the innate and the adaptive immune system. They influence a multitude of cellular processes ranging from specific immune cell functions to proliferation and differentiation, thereby controlling a wide range of immune functions. ${ }^{30}$ It thus is justified to expect that miRNAs could serve as efficient biomarkers not only for the detection of early sepsis but also for distinguishing the hyperinflammatory and the immunosuppressive phases of sepsis. Accordingly, a number of studies aiming at the identification of miRNAs that are differentially expressed in sepsis versus healthy controls and in nonsurvivors versus survivors have been published during the last few years. In these studies, the expression of miRNAs was profiled either in plasma/serum or whole blood or in purified blood cells. For example, in whole blood, miR-155 and miR-21 were shown to be elevated in sepsis, while miR-150 was found to be downregulated. ${ }^{31-33}$ In other studies investigating serum or plasma samples, miR-223, miR-143, and miR-34a were upregulated, ${ }^{34,35}$ and miR-146a and miR-15a were downregulated. ${ }^{34,36}$ Some authors chose a more specific approach and analyzed cells of the adaptive immunity. In these studies, sepsis patients exhibited elevated miR-15a/16 and miR-223 and reduced miR-146a and miR31 expression levels. ${ }^{37-39}$ Some studies were able to detect correlations between expression levels of specific miRNAs (eg, miR-233, miR-150, miR-547-5p, miR-133a) and the severity of sepsis. ${ }^{40,41}$ Additionally, to enable an early diagnostic differentiation and a specific therapeutic approach, several recent studies aimed at using miRNAs to distinguish between sepsis and the Systemic Inflammatory Response Syndrome. ${ }^{42-44}$ A comprehensive summary of miRNAs that have been identified as differentially expressed in sepsis patients as compared to healthy individuals so far is given in the articles by Kingsley and Bhat ${ }^{45}$ and Neudecker et al. ${ }^{46}$

To date, it is not clear which cell types are the origins of free circulating miRNAs in sepsis and whether other coexisting morbidities (eg, tumors) set free miRNAs that might strongly bias the sepsis-specific expression profiles. Due to these uncertainties and to the rather small sample sizes of most studies, it currently is not clear which of the proposed miRNA biomarkers will reveal as reliable diagnostic tools in the diagnosis and treatment of sepsis in the future. 
Elucidation of the molecular mechanisms underlying specific miRNA alterations in sepsis is a conditio sine qua non to (i) acquire a comprehensive understanding of the pathomechanisms underlying sepsis, and to (ii) develop miRNA-based therapy approaches. A large number of in vitro and animal studies dealing with these issues have been published during the last decade, which provided profound insights into the networks of miRNA signaling within the immune system generally and in particular regarding the pathophysiology of sepsis. It has become clear that miRNAs are hubs within the regulatory circuitries of inflammatory responses. They target central transcription factors such as NF- $\mathrm{KB}$ or hypoxia-inducible factor 1-alpha, cell surface receptors such as toll-like receptors, or intracellular signaling cascades such as mitogen-activated protein kinase pathways. Also, direct targeting of cytokines and/or their receptors is a frequently occurring phenomenon. As a result, development, function, and differentiation of both adaptive and innate immune cells are affected, which impacts both hyperinflammation and immunosuppression in sepsis. Which side of the coin will be more pronounced depends on the individual miRNA expression profiles, the regulated target genes, and, importantly, the cellular environment. For example, many miRNAs that have been identified as clinical markers in sepsis have experimentally been validated as regulators of the NF-кB-pathway (Figure 2, Table 1): miR31 targets the NF- $\kappa \mathrm{B}$ inducing kinase, ${ }^{47} \mathrm{miR}-146 \mathrm{a}$ and $\mathrm{miR}-$ $15 \mathrm{a} / 16$ target the interleukin-1 receptor-associated kinase $1,{ }^{49,56} \mathrm{miR}-223, \mathrm{miR}-15 \mathrm{a} / 16$ target the IкB kinase alpha, ${ }^{50}$ and miR-155 controls expression of the transforming growth factor (TGF)-beta-activated kinase 1/MAP3K7-binding protein $2 .{ }^{59}$ The NF- $\mathrm{KB}$ family of transcription factors controls a multitude of contributors to the inflammatory response, such as proinflammatory cytokine production, leukocyte recruitment, or cell survival, and is also involved in the feedback control of inflammation. ${ }^{64,65}$ Thus, these miRNAs can be considered important players within the inflammatory networks regulated by NF- $\kappa B$ influencing magnitude and duration of inflammation during sepsis.

The most important miRNAs known in the context of sepsis so far and their functions in immune cells, as well as the respective literature, are summarized in Table 1 . It has to be kept in mind, however, that neither mouse models nor in vitro experiments with cell lines or primary cells fully cover the functional networks of the human organism. ${ }^{66,67}$ Thus, miRNAs in the context of human sepsis can only be considered "guilty by association," and the exact impact of these miRNAs on the inflammatory responses during the different stages of sepsis needs to be fully elucidated.

\section{ACUTE LUNG INJURY}

ALI is orchestrated by activated immune cells and by excess cytokine and protease release into the alveolar space. ${ }^{68}$ Given these conditions, immunomodulatory miRNAs proposed as biomarkers in sepsis might also be of diagnostic value in ALI. Additionally, miRNAs affecting epithelial and endothelial cells might play a role. Surprisingly, unlike in sepsis, clinical studies evaluating miRNAs as possible biomarkers in ALI are scarce. One study analyzing blood samples of 45 patients with ARDS induced by cardiopulmonary bypass found differential expression of a set consisting of 6 upregulated and 5

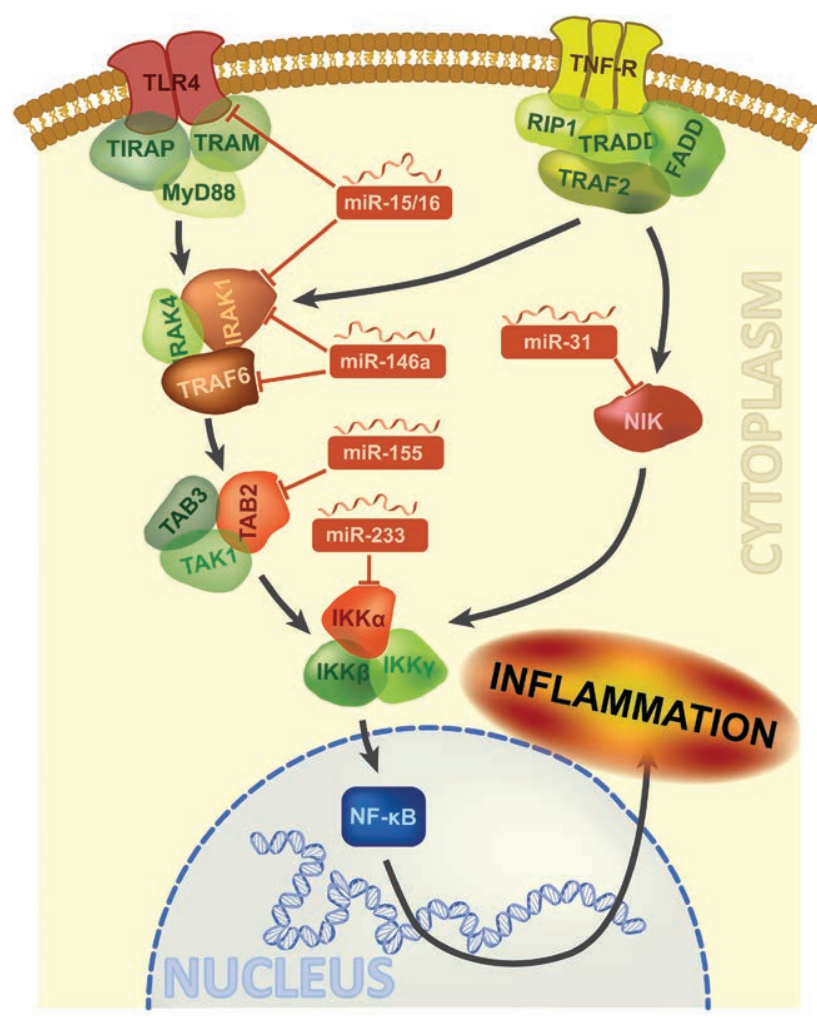

Figure 2. miRNAs target central components of the nuclear factor$\kappa B(N F-\kappa B$ ) signaling pathway thereby regulating the inflammatory response in sepsis. FADD indicates fas-associated protein with death domain; IKK, IKB kinase alpha; IRAK, interleukin-1 receptorassociated kinase; NIK, NF-KB inducing kinase; RIP1, receptor-interacting serine/threonine proteinkinase 1; TAB, TGF-beta-activated kinase 1/MAP3K7-binding protein 2; TAK, tat-associated kinase; TGF, transforming growth factor; TIRAP, toll-interleukin 1 receptor domain containing adaptor protein; TLR4, toll-like receptor-4; TNF-R, tumor necrosis factor receptor; TRADD, TNF receptor type 1-associated death domain; TRAF, TNF receptor-associated factor 2; TRAM, toll-like receptor adaptor molecule.

downregulated miRNAs. ${ }^{69}$ If these miRNAs might reveal as suitable biomarkers still needs to be determined.

There exist a variety of animal studies investigating the role of miRNAs in the pathogenesis of ALI. Data were mostly derived from rodents subjected to ALI induced by intratracheal injection of lipopolysaccharide (LPS), acid, or bacteria, or by ventilator trauma. In these studies, a large number of different miRNAs was found to be differentially regulated (extensively reviewed in the study by Rajasekaran et $\mathrm{al}^{70}$ ); however, a consensus regarding the value of these miRNAs in the development and resolution of ALI has not yet been achieved. ALI animal models have also been used to investigate miRNA treatment approaches in a surprisingly high number of studies, which is most likely due to the fact that an easy-to-handle and specific application of miR-mimics or anti-miRs via the airways is possible. In these studies, several miRNAs have been evaluated with respect to their capacity to influence the course of ALI. ${ }^{70}$ Interestingly, 3 of those inflammation-related miRNAs relevant in sepsis revealed also here as promising therapeutic targets: in LPS-mediated injury, anti-miR-155 application significantly reduced the numbers of inflammatory cells and the levels of proinflammatory cytokines in bronchoalveolar lavage, ${ }^{71}$ 
Table 1. Mechanisms of Action of miRNAs Identified as Sepsis Biomarkers

\begin{tabular}{|c|c|c|c|c|}
\hline & Targets & Regulated Signaling Pathways & Regulation in Sepsis Patients & References \\
\hline miR-31 & FIH, NIK, SAP & HIF-1 $\alpha$, NF-אB, SLAM & T cells $\Omega$ & $37,47,48$ \\
\hline miR-15a/16 & TLR4, IRAK 1, IKK- $\alpha$ & TLRs, IL-1, NF-кB & PBMCs 仓̂ & $34,49,50$ \\
\hline miR-21 & PDCD4, SORBS2, IL-12 & Apoptosis, STAT & Blood $\hat{\imath}$ & $33,51,52$ \\
\hline miR-143 & IL13R, TLR2, COX-2 & STAT, TLR, prostaglandins & Serum î & $34,53-55$ \\
\hline miR-146a & IRAK, TRAF6, PRKCE & IL-1, TNF, calcium signaling, NF-KB & Serum, $\mathrm{T}$ cell $\Omega$ & $34,38,56$ \\
\hline miR-150 & HIF-1 $\alpha$, VEGFA, ARRB2 & HIF-1 $\alpha$, angiogenesis, signal inhibition & Blood $\sqrt{2}$ & $43,57,58$ \\
\hline miR-155 & SOCS1, SHIP1, TAB2 & STAT, PI3K, AKT, NF-кB & Blood 仓̂ & $31,59-61$ \\
\hline miR-223 & $\begin{array}{l}\text { NLRP3, NFI-A, IGF-1R, STAT3, } \\
\text { FOXO1, IKK- } \alpha\end{array}$ & IL-1, DNA-binding, PI3, AKT, STAT, NF-אB & Serum, PBMCs $\hat{\imath}$ & $39,50,62,63$ \\
\hline
\end{tabular}

Abbreviations: AKT, protein kinase B; ARRB2, arrestin beta 2; COX-2, cyclooxygenase-2; FIH, factor inhibiting hypoxia; FOX01, forkhead box protein 01; HIF$1 \alpha$, hypoxia-inducible factor 1-alpha; IGF-1R, insulin-like growth factor receptor 1; IKK- $\alpha$, I-kappaB kinase alpha; IL, interleukin; IRAK, interleukin-1 receptorassociated kinase; NF-kB, nuclear factor-kB; NFl-a, nuclear factor 1A; NIK, NF-KB-inducible kinase; NLRP3, NACHT, LRR and PYD domains-containing protein 3; PBMC, peripheral blood mononuclear cells; PCDC4, programmed cell death 4; PI3K, phosphatidylinositide-3-kinase; PRKCE, protein kinase C epsilon; PTGS2, prostaglandin-endoperoxide synthase 2; SAP, SLAM-associated protein; SHIP1, phosphatidylinositol-3,4,5-trisphosphate 5-phosphatase 1; SLAM, signaling lymphocyte activation molecule; SOCS1, suppressor of cytokine signaling 1; SORBS2, Sorbin and SH3 domain containing protein 2; STAT3, signal transducer and activator of transcription 3; TAB2, TGF-beta-activated kinase 1/MAP3K7-binding protein; TLR, toll-like receptor; TNF, tumor necrosis factor; TRAF, TNF receptorassociated factor; VEGFA, vascular endothelial growth factor A.

which was further corroborated in miR-155 $5^{-/-}$mice, thus suggesting a role of miR-155 as a driver of lung inflammation. ${ }^{72}$ miR-146a and miR-125b, on the other hand, were found to ameliorate lung injury. miR-146a-mimic application suppressed both LPS- and acid-induced expression of proinflammatory cytokines and inducible nitric oxide synthase. ${ }^{73,74}$ Overexpression of miR-125b reduced lung permeability and expression of proinflammatory mediators and improved mice survival. ${ }^{75}$ Both miRNAs thus have been suggested as potential therapeutic targets for ALI. Similar to sepsis, miRNAs hold promise to become valuable biomarkers and therapy tools in the future; however, additional studies will be required to assess these issues.

\section{ACUTE ORGAN FAILURE}

Acute failure of liver, kidney, and heart are important clinical complications in intensive care medicine, with high mortality rates. Also here, miRNAs are increasingly gaining attention because biomarkers enabling an early and exact diagnosis and prognostic estimation, as well as innovative therapy approaches, are strongly needed.

Several miRNAs are specifically expressed or enriched in the liver, with miR-122 being the most abundant liver-specific miRNA. Both acute and chronic liver damage are associated with hepatocyte cell death, which leads to the release of liverspecific miRNAs. Starkey Lewis et al found substantially elevated plasma levels of miR-122 and miR-192 in acetaminophen-induced acute liver injury. ${ }^{76}$ Determination of miR-122 significantly outperformed alanine aminotransferase (ALT), international normalized ratio (INR), and acetaminophen plasma concentrations for the prediction of this type of liver injury. ${ }^{77}$ In a study evaluating miRNAs in liver steatosis, miR122 was found to correlate with the severity of the disease. ${ }^{78}$ In chronic hepatitis $\mathrm{C}$, the typical inflammation-related miRNAs miR-155, miR-125b, and miR-146a were increased in patients' plasma. ${ }^{79}$ As liver-specific delivery of nucleic acids by microparticles has successfully been demonstrated by Press et al, ${ }^{80}$ therapeutic approaches using miRNA mimics or antagonists are conceivable in the near future.

The intestine is a unique organ where multiple communications between the immune system, gut epithelium, and commensal microbiota take place. A breakdown of homeostasis can lead to inflammatory disorders as frequently seen in the perioperative context. Biomarkers indicating the onset of acute gut injury are scarce, and miRNAs are currently one of the most promising molecules in this field. To date, however, available data are mainly derived from models of inflammatory bowel disease (IBD). For example, a very recent study using a murine model of dextrane sodium sulfate-induced colitis shed light on the pivotal function of miR-223 in IBD: administration of miR-223 mimics inhibited the NLRP3 inflammasome, thereby reducing interleukin- $1 \beta$-mediated dextrane sodium sulfate-induced colitis. ${ }^{81}$ These findings are consistent with clinical data reporting miR-223 to be elevated in a subset of patients experiencing IBD, ${ }^{82}$ thus suggesting miR-223 as a potent new biomarker for gut inflammation. Further studies are needed to clarify whether these findings can be transferred into the acute perioperative setting.

In acute kidney injury (AKI), many miRNAs have been shown to be involved in the amplification or reduction of acute injury processes. While molecular mechanisms have only been investigated in animal studies so far (extensively reviewed in the article by Fan et $\mathrm{al}^{13}$ ), a considerable number of clinical studies have provided data on the potential of certain miRNAs to serve as markers of early AKI. Specifically, miR-21 has been revealed as stable biomarker: urine and plasma miR-21 levels have been shown to correlate with AKI severity and hospital mortality and to predict the probability of postoperative renal replacement therapy. Also, lower baseline plasma levels of miR-21 have been shown to predict AKI after cardiac surgery. ${ }^{84,85}$ In animal models of AKI, overexpression of miR-21 provided renoprotection, thus suggesting this miRNA as a therapeutic target. ${ }^{86,87}$ Further, decreased serum levels of the kidney-enriched miRNAs miR-29a, miR-101-3p, and miR-127a have been shown to predict AKI in intensive care unit patients. ${ }^{88}$ Even in AKI, anti-inflammatory miR-146a plays an important role, as decreased blood levels have been shown to be a predictor of AKI in the intensive care unit. ${ }^{88}$

Research on the role of miRNAs as biomarkers for different cardiovascular disease entities has exponentially expanded during the last few years, and miRNAs have been suggested as new biomarkers providing additional information to established protein-based markers such as cardiac troponins and natriuretic peptide. A large number of encouraging results have been obtained so far, which have extensively been reviewed before. ${ }^{89,90}$ Here, we will focus on 
the description of the most striking miRNAs in myocardial infarction (MI) and heart failure.

In acute MI, miRNAs with high myocardial expression are released into the peripheral circulation, which opens up new opportunities of improving diagnostic discriminatory power and/or accelerate diagnosis by determination of specific miRNAs in the peripheral blood of patients suspicious of MI. ${ }^{91}$ For example, the cardiac-specific miR-208b is detectable within 3 hours after MI and may persist elevated for as long as 90 days. In several studies, miR-208b was revealed as a useful early biomarker for MI. ${ }^{92,93}$ Also, a signature consisting of 6 miRNAs was revealed as a reliable predictor of MI, with an AUC significantly exceeding troponin $C$ and creatine kinase-MB. ${ }^{44}$ In MI, miRNAs were also shown to exert predictive impact: in 2 large cohorts, an miRNA set consisting of miR-126, miR-197, and miR-233 was identified to reliably predict $\mathrm{MI}$ in persons with coronary artery disease. ${ }^{95,96}$

In heart failure, miRNAs miR-558, mR122*, and miR520-d-5p were identified in a cohort of 53 patients as a stable biomarker set to predict the diagnosis "nonischemic heart failure. ${ }^{\prime 97}$ In another study comprising 42 patients experiencing heart failure, miR-182 was identified to predict mortality with higher prognostic power than NT-proBNP and high-sensitive C-reactive protein..$^{98}$ Taken together, miRNAs are clearly on the verge of implementation in the prediction and diagnosis of AKI, MI, and heart failure and may be a valuable future tool in intensive care medicine.

\section{MIRNAS IN ANESTHESIA AND POSTOPERATIVE CARE}

In animal models, commonly used anesthetic drugs (eg, propofol, sevoflurane, and ketamine) have been found to induce neurotoxic effects such as neurodegeneration, neural apoptosis, and impairment of neural stem-cell self-renewal. ${ }^{99-101}$ Recent research identified miRNAs as one of the key players mediating neurotoxic or protective effects. ${ }^{102}$ In 2014, Goto et $\mathrm{al}^{103}$ discovered in rodents that propofol and sevoflurane administration substantially altered miRNA expression profiles. These results made the pace for further rodent studies in this area. For example, it was shown that administration of propofol induces downregulation of miR-21 and induction of miR-665, leading to impairment of neuronal differentiation and induction of apoptosis. ${ }^{104,105}$ For isoflurane, downregulation of miR-214 and let-7d was reported, leading to an increase of apoptosis via induction of $\mathrm{Bax}^{106,107}$ and in ketamine anesthesia, miRNA expression patterns could be associated with hippocampal neurodegeneration and memory impairment. ${ }^{108,109}$

Taken together, a large body of animal studies suggests that commonly used drugs for induction and maintenance of anesthesia induce alterations in miRNA expression, which might deteriorate neuronal integrity and neurocognitive processes such as memory and learning. Whether these experimental findings may also be true for the human organism needs to be investigated in the near future.

In postoperative care, reliable biomarkers that allow for prediction or at least timely detection of complications are needed. Generally, miRNA markers of acute organ injury as described above may also be of considerable predictive value in this setting. With regard to specific postoperative complications, only a few studies addressing miRNAs as possible biomarkers are available so far: for example, a study
Table 2. Different Detection Platforms Currently Used in miRNA Diagnostics and Research

\begin{tabular}{|c|c|c|}
\hline Detection Method & Features & References \\
\hline qRT-PCR & $\begin{array}{l}\text { Cost-efficient } \\
\text { High sensitivity, accuracy, } \\
\quad \text { reproducibility } \\
\text { Widely available } \\
\text { Automatable } \\
\text { Fast method }\end{array}$ & 131-133 \\
\hline Microarray & $\begin{array}{l}\text { Multiple microRNA analyses in } \\
\text { parallel } \\
\text { Discovery of microRNA signatures } \\
\text { Not suitable for high throughput }\end{array}$ & 134,135 \\
\hline NGS & $\begin{array}{l}\text { Highly precise } \\
\text { Discovery of unknown sequences } \\
\text { Time-consuming data processing } \\
\text { Cost-intensive }\end{array}$ & 136,137 \\
\hline SPR & $\begin{array}{l}\text { Highly sensitive } \\
\text { Very fast } \\
\text { Suitable for point-of-care analysis } \\
\text { Still in the stage of development }\end{array}$ & 138,139 \\
\hline
\end{tabular}

Abbreviations: NGS, next-generation sequencing; qRT-PCR, quantitative reverse transcription polymerase chain reaction; SPR, surface plasmon resonance.

investigating 30 children after heart surgery revealed a set of 3 miRNAs (208a, 208b, and 499) as possible biomarkers for early detection of postoperative myocardial damage. ${ }^{110}$ Also, miRNA-499 was identified as a marker for postoperative MI in 30 patients undergoing coronary artery bypass grafting. ${ }^{111}$ Several ongoing studies are evaluating the suitability of miRNAs as biomarkers in postoperative care, for example, as predictors of postoperative delirium (ClinicalTrials.gov). Taken together, miRNAs may serve as valuable biomarkers in the postoperative setting in the near future.

\section{MIRNAS IN PAIN}

Pain plays a central role in perioperative care. Several classifications of pain exist, the broadest one being the distinction between acute and chronic pain, with a subclassification of the latter into inflammatory versus neuropathic. Chronic pain syndromes greatly contribute to the overall cost for the medical system, ${ }^{112,113}$ and both diagnostic and treatment options are limited, not at least due to lack of understanding of its pathophysiology. In 2007, a first study reported the downregulation of $7 \mathrm{miRNAs}$ in the trigeminal rat ganglion after inducing inflammatory pain in the masseter muscle. ${ }^{114}$ Since then, noncoding RNA molecules have been acknowledged to play a critical part in especially chronic pain pathophysiology.

The dorsal root ganglion (DRG) has been identified as a key structure involved in the pathophysiology of neuropathic pain processing, ${ }^{115,116}$ and spinal nerve ligation leads to changes of both the proteome $\mathrm{e}^{117}$ and the transcriptome ${ }^{118}$ of this structure. Evidence for miRNA involvement was presented by Zhao et $\mathrm{al}^{119}$ in 2010 , who reported that miRNA function seems to primarily impact inflammatory pain. A global reduction of miRNA expression levels via Dicer knockdown leads to the downregulation of several nociceptor-associated proteins crucial for development and maintenance of hyperalgesia. ${ }^{120,121}$ Shortly after, a number of proteins connected to pain recognition, such as CACNA2D1, SCN11A, and P2RX4, were found to be regulated by miRNAs. ${ }^{115,119,122,123}$ 


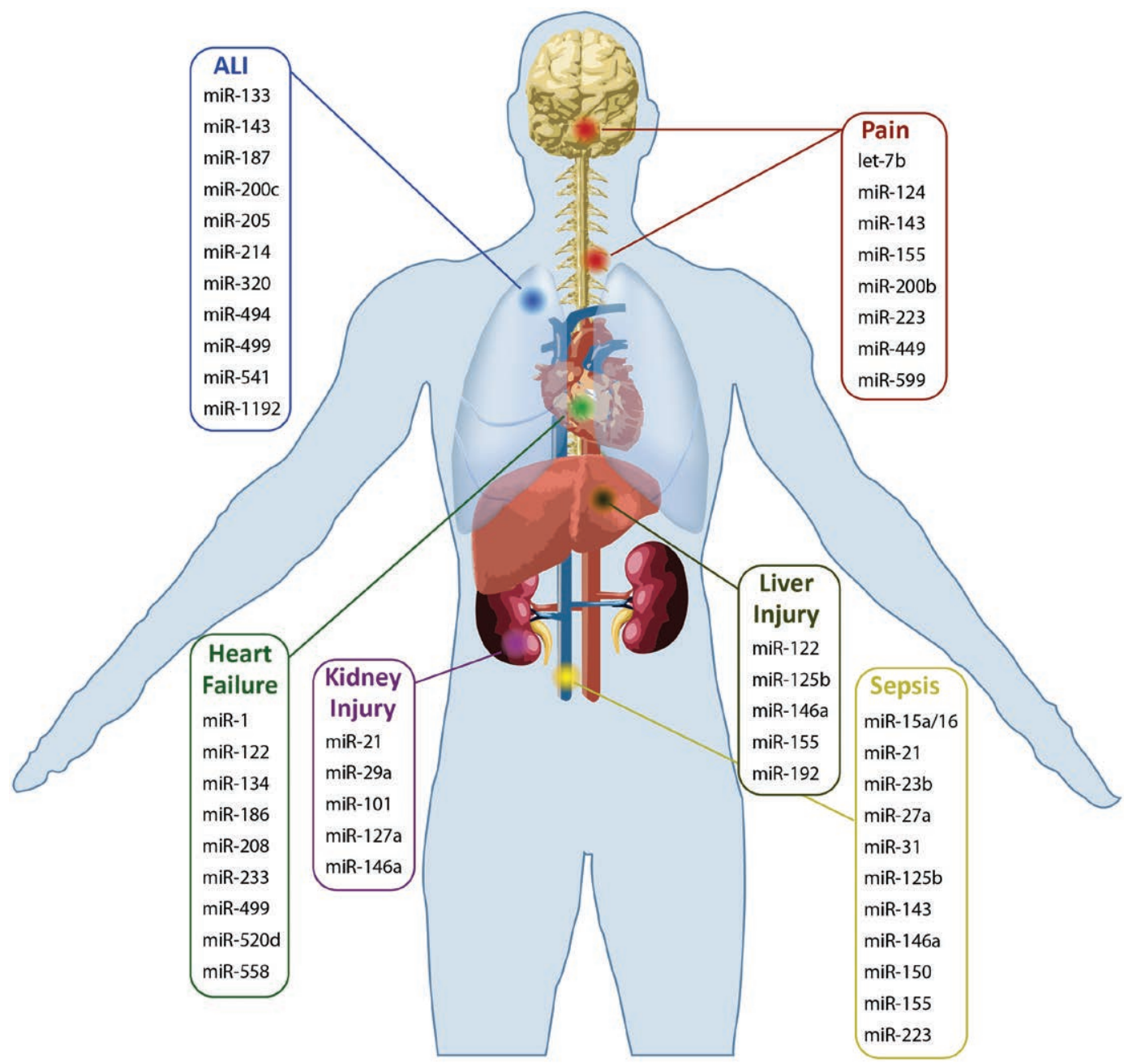

Figure 3. Overview of miRNAs involved in the pathogenesis of organ failure, sepsis, and pain syndromes, which are also considered as possible specific biomarkers.

miRNAs can also directly trigger pain sensation. Based on the observation that miRNAs circulating in blood and cerebrospinal fluid can aggravate neurodegeneration, ${ }^{124}$ Park et al ${ }^{125}$ found that extracellular miRNAs could induce rapid onset of pain via induction of rapid inward currents in DRG neurons. This effect was mainly mediated by tolllike receptor-7 that recognized the single-strand RNA motif GUUGUGU in the mature sequences of hsa-let-7b and hsamiR-599. ${ }^{125}$ Interestingly, let-7b is highly enriched in DRG neurons and is released upon neuronal activity ${ }^{125}$ and has also been linked to complex regional pain syndrome. ${ }^{126}$ The ultimate location for pain processing is the central nervous system, and it is hardly astonishing that miRNAs related to central pain processing have been described. Pohl et al ${ }^{127}$ focused on the investigation of the effects of inflammatory pain on the prefrontal cortex that is activated in acute as well as chronic pain, finding significantly increased levels of miR-155 and miR-223. In a more functional approach, Imai et $\mathrm{al}^{128}$ combined functional MRI, in silico analyses, and laboratory methods to draw a connection between neuropathic pain that decreases the expression of $\mathrm{miR}-200 \mathrm{~b} / \mathrm{miR}-449$ and the mesolimbic circuitry via unleashed expression of DNA methyltransferase $3 a$.
In summary, miRNAs are evidently involved in major known pathways relevant to pain development and maintenance ${ }^{113}$ and may support therapeutic decisions someday as exemplified by hsa-miR-124 expression in CD4 T cells that has been found to be predictive of treatment response in chronic lower back pain. ${ }^{129}$

\section{CURRENT USE OF MIRNAS AS CLINICAL BIOMARKERS AND THERAPEUTIC TOOLS} miRNAs as Biomarkers

Despite the multitude of miRNAs that have been proposed as possible biomarkers, determination of miRNAs has not made its way into clinical practice so far. This is, indeed, surprising and mainly due to the fact that a universal measuring method enabling an easy-to-handle, fast, reliable, and inexpensive determination of miRNAs does not exist to date. miRNA expression profiling is a technical challenge: miRNAs are tiny molecules, miRNA family members exhibit a high degree of homology, and absolute miRNA concentrations in body fluids are rather low. Several measurement platforms are currently available to determine relative miRNA abundance in biological samples using different technologies such as small RNA sequencing, 
reverse transcription quantitative polymerase chain reaction, and microarray hybridization. Each method has its strengths and weaknesses, and selection of the measuring method depends on the specific scientific questions to be addressed. ${ }^{130}$ The different detection platforms currently used in miRNA diagnostics and research are briefly summarized in Table 2.

Moreover, to ensure reliable miRNA measurement, it is necessary to carefully choose the compartment most suitable for measuring the miRNAs of interest (eg, serum, plasma, blood cells, tissue specimens, or body fluids such as urine or liquor) and to select an appropriate normalization strategy. ${ }^{140}$ Also, it has to be taken into account that miRNA expression profiles are influenced by genetic heterogeneity and exogenous influences, such as medication, nutrition, or exposure to certain environmental conditions. ${ }^{141,142}$

In the field of perioperative medicine, multi-institutional studies adhering to standardized protocols for sample preparation, miRNA detection, and data analysis are required to clearly make out those miRNAs qualifying as valid biomarkers for future clinical use (possible miRNA candidates are summarized in Figure 3). Actually, we are very close to an implementation of miRNAs into the daily clinical use, which will provide valuable complementary data on our roads toward a personalized medicine.

\section{miRNA-Based Therapy}

The concept of inhibiting or overexpressing miRNAs for therapeutic purposes represents a new frontier in modern medicine. To date, first approaches-either using miRNA mimics or miR-inhibitors-have made their way into clinical studies so far.

Synthetic miRNAs that mimic natural miRNAs are supposed to exert therapeutic effects by reconstituting miRNAs that are downregulated during disease or by downregulating signaling pathways involved in disease pathology. miRNA mimics are double-stranded oligonucleotides that require liposomes, lipoprotein-based carriers, or nanoparticles as vehicles for their delivery. ${ }^{143,144}$ The first miRNA mimic to enter a clinical study in the field of oncology was MRX34. This substance was designed to deliver a mimic of the naturally occurring tumor suppressor miR-34, which is underexpressed in a wide variety of cancers. MRX34 was tested in a multicenter phase 1 clinical trial starting 2013, which included patients with primary liver cancer, other solid cancers, and hematological malignancies. Results of this study are elusive, as it was stopped in 2016 due to multiple immune-related severe adverse events. Very recently, a phase 1 study evaluating the miRNA mimic MRG-201 was initiated. This substance is designed to mimic miR-29b, thereby decreasing the expression of collagen and other proteins that are involved in fibrous scar formation, and is applied in healthy volunteers by intradermal injection.

Pharmacologic approaches of miRNA inhibition exert therapeutic effects by use of anti-miRs or miRNA sponges. Both classes of molecules block natural miRNAs and thus are supposed to silence miRNAs that are elevated during disease or to disinhibit signaling pathways involved in disease pathology. Anti-miRs are single-stranded oligonucleotides that are chemically modified to enhance target

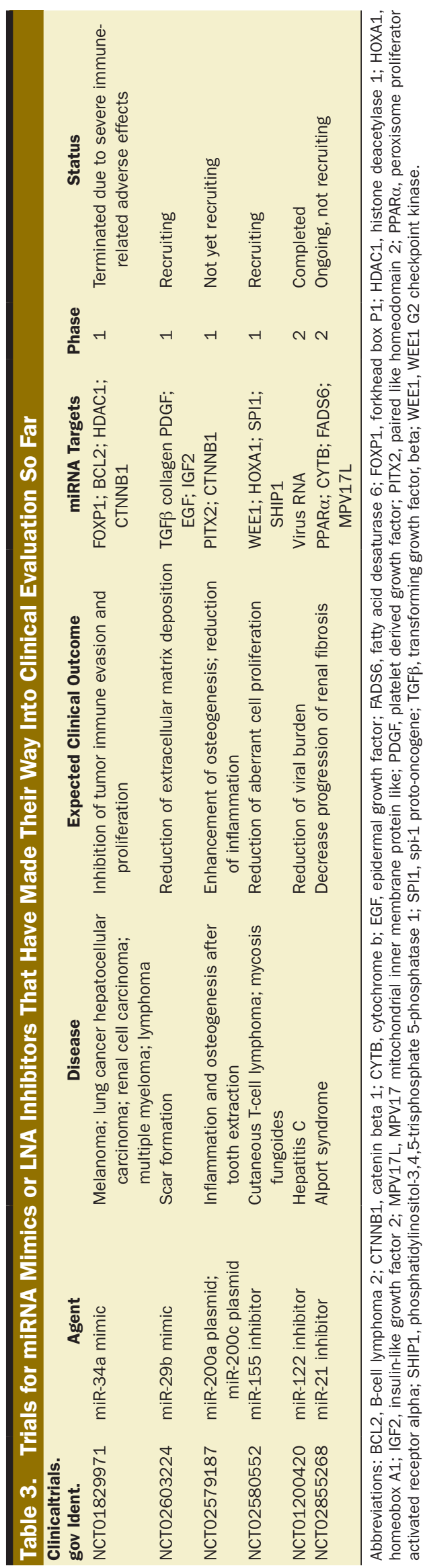


affinity, stability, and tissue uptake. ${ }^{143,144}$ Unlike doublestranded miRNA mimics, anti-miRs can be administered dissolved in saline solution. Once entering the circulation, they are easily taken up by multiple tissues and organs, where they specifically bind to endogenous miRNAs thus reducing their availability. Sponges are RNA molecules that contain multiple seed sites of a specific miRNA that act as competitive inhibitors by "hoovering" endogenous miRNAs.

The prime example of a successful therapeutic antimiRNA approach is miravirsen, an LNA-modified antimiR-122 that effectively combats a hepatitis C virus infection. ${ }^{145}$ Miravirsen targets the liver-specific miR-122, which is "hijacked" by the hepatitis C virus to bind to sequences in the 5'-UTR of the viral RNA, thereby enhancing virus replication. In a first phase 2 a clinical trial enrolling 36 patients with chronic hepatitis $\mathrm{C}$, miravirsen treatment showed a dose-dependent antiviral activity clearly exceeding the time of therapy. Notably, in 4 of 9 patients receiving the highest doses, stable seroconversion was achieved. In this clinical trial, no adverse side effects were reported. Further evaluation of miravirsen is a topic of several ongoing studies.

Another substance that very recently entered clinical phase 1 evaluation is MRG-106, an LNA anti-miR of miRNA-155. In hematological malignancies, miRNA-155 plays a key role in differentiation, function, and proliferation of blood and lymphoid cells, and inhibition of miRNA155 in lymphoma cells reduced proliferation in vitro. The phase 1 trial of MRG-106 enrolls patients experiencing cutaneous T-cell lymphoma and aims at assessing safety, tolerability, and molecular effects of MRG-106 in the lesions of MF patients. Trials for miRNA mimics or LNA inhibitors that have made their way into clinical evaluation so far are summarized in Table 3.

Currently, miRNA-based therapy still is in its infancy and a number of problems have to be addressed until a broad, reliable, and safe clinical use will be a feasible objective. The development of delivery systems enabling cell-specific uptake and the design of therapeutical molecules without toxic side effects remain a major challenge. Moreover, unwanted off-target effects have to be minimized. After taking these hurdles, miRNA-based therapy strategies will open up one of the most innovative and promising perspectives in current medicine.

\section{CONCLUSIONS}

It is to be expected that miRNAs will find their way as very helpful new biomarkers and as effective therapy tools into the clinical routine in the near future. This will help to strike out on new paths, which-not least in perioperative medicine-will entail significant medical improvements. $\#$

\section{DISCLOSURES}

Name: Simone Kreth, MD, PhD.

Contribution: This author helped write the manuscript. Name: Max Hübner, MD.

Contribution: This author helped write the manuscript.

Name: Ludwig Christian Hinske, MD.

Contribution: This author helped write the manuscript and prepare all figures in the manuscript.

This manuscript was handled by: Alexander Zarbock, MD.

\section{REFERENCES}

1. Lee RC, Feinbaum RL, Ambros V. The C. elegans heterochronic gene lin-4 encodes small RNAs with antisense complementarity to lin-14. Cell. 1993;75:843-854.

2. Bartel DP. MicroRNAs: genomics, biogenesis, mechanism, and function. Cell. 2004;116:281-297.

3. Lagos-Quintana $M$, Rauhut $R$, Lendeckel $W$, Tuschl $T$. Identification of novel genes coding for small expressed RNAs. Science. 2001;294:853-858.

4. Kozomara A, Griffiths-Jones S. miRBase: integrating microRNA annotation and deep-sequencing data. Nucleic Acids Res. 2011;39:D152-D157.

5. Hinske LC, França GS, Torres HAM, et al. miRIAD—integrating micro RNA inter- and intragenic data. Database. 2014;2014. Available at: https://academic.oup.com/database/article/ doi/10.1093/database/bau099/2635266/miRIAD-integratingmi-cro-R-NA-i-nter-a-nd. Accessed April 30, 2017.

6. Martirosyan A, De Martino A, Pagnani A, Marinari E. ceRNA crosstalk stabilizes protein expression and affects the correlation pattern of interacting proteins. Sci Rep. 2017;7:43673.

7. Lee $Y$, Kim M, Han J, et al. MicroRNA genes are transcribed by RNA polymerase II. EMBO J. 2004;23:4051-4060.

8. Han J, Lee Y, Yeom KH, Kim YK, Jin H, Kim VN. The DroshaDGCR8 complex in primary microRNA processing. Genes Dev. 2004;18:3016-3027.

9. Han J, Lee Y, Yeom KH, et al. Molecular basis for the recognition of primary microRNAs by the Drosha-DGCR8 complex. Cell. 2006;125:887-901.

10. Lund E, Güttinger S, Calado A, Dahlberg JE, Kutay U. Nuclear export of microRNA precursors. Science. 2004;303:95-98.

11. Hutvágner G, McLachlan J, Pasquinelli AE, Bálint E, Tuschl $\mathrm{T}$, Zamore PD. A cellular function for the RNA-interference enzyme Dicer in the maturation of the let-7 small temporal RNA. Science. 2001;293:834-838.

12. Schwarz DS, Hutvágner G, Du T, Xu Z, Aronin N, Zamore PD. Asymmetry in the assembly of the RNAi enzyme complex. Cell. 2003;115:199-208.

13. Guo H, Ingolia NT, Weissman JS, Bartel DP. Mammalian microRNAs predominantly act to decrease target mRNA levels. Nature. 2010;466:835-840.

14. Eichhorn SW, Guo H, McGeary SE, et al. mRNA destabilization is the dominant effect of mammalian microRNAs by the time substantial repression ensues. Mol Cell. 2014;56:104-115.

15. Gurtan AM, Sharp PA. The role of miRNAs in regulating gene expression networks. J Mol Biol. 2013;425:3582-3600.

16. Wang X, El Naqa IM. Prediction of both conserved and nonconserved microRNA targets in animals. Bioinformatics. 2008;24:325-332.

17. Nana-Sinkam SP, Croce CM. MicroRNA regulation of tumorigenesis, cancer progression and interpatient heterogeneity: towards clinical use. Genome Biol. 2014;15:445.

18. Boon RA, Dimmeler S. MicroRNAs in myocardial infarction. Nat Rev Cardiol. 2015;12:135-142.

19. Issler O, Chen A. Determining the role of microRNAs in psychiatric disorders. Nat Rev Neurosci. 2015;16:201-212.

20. Liao Q, Wang B, Li X, Jiang G. miRNAs in acute myeloid leukemia. Oncotarget. 2017;8:3666-3682.

21. Pfeffer SR, Yang CH, Pfeffer LM. The role of miR-21 in cancer. Drug Dev Res. 2015;76:270-277.

22. Garo LP, Murugaiyan G. Contribution of microRNAs to autoimmune diseases. Cell Mol Life Sci. 2016;73:2041-2051.

23. Valadi H, Ekström K, Bossios A, Sjöstrand M, Lee JJ, Lötvall JO. Exosome-mediated transfer of mRNAs and microRNAs is a novel mechanism of genetic exchange between cells. Nat Cell Biol. 2007;9:654-659.

24. Zhang Y, Liu D, Chen X, et al. Secreted monocytic miR150 enhances targeted endothelial cell migration. Mol Cell. 2010;39:133-144.

25. Hergenreider E, Heydt S, Tréguer K, et al. Atheroprotective communication between endothelial cells and smooth muscle cells through miRNAs. Nat Cell Biol. 2012;14:249-256.

26. Mitchell PS, Parkin RK, Kroh EM, et al. Circulating microRNAs as stable blood-based markers for cancer detection. Proc Natl Acad Sci U S A. 2008;105:10513-10518. 
27. Hayes J, Peruzzi PP, Lawler S. MicroRNAs in cancer: biomarkers, functions and therapy. Trends Mol Med. 2014;20:460-469.

28. Devaux Y, Stammet P, Friberg H, et al; Biomarker subcommittee of TTM trial (Target Temperature Management After Cardiac Arrest, NCT01020916). MicroRNAs: new biomarkers and therapeutic targets after cardiac arrest? Crit Care. 2015;19:54.

29. Adams BD, Parsons C, Walker L, Zhang WC, Slack FJ. Targeting noncoding RNAs in disease. J Clin Invest. 2017;127:761-771.

30. Mehta A, Baltimore D. MicroRNAs as regulatory elements in immune system logic. Nat Rev Immunol. 2016;16:279-294.

31. Liu J, Shi K, Chen M, et al. Elevated miR-155 expression induces immunosuppression via CD39(+) regulatory T-cells in sepsis patient. Int J Infect Dis. 2015;40:135-141.

32. Sheng B, Zhao L, Zang X, Zhen J, Chen W. miR-375 ameliorates sepsis by downregulating miR-21 level via inhibiting JAK2STAT3 signaling. Biomed Pharmacother. 2017;86:254-261.

33. Wang H, Bei Y, Shen S, et al. miR-21-3p controls sepsis-associated cardiac dysfunction via regulating SORBS2. J Mol Cell Cardiol. 2016;94:43-53.

34. Goodwin AJ, Guo C, Cook JA, Wolf B, Halushka PV, Fan H. Plasma levels of microRNA are altered with the development of shock in human sepsis: an observational study. Crit Care. 2015;19:440.

35. Wang HJ, Zhang PJ, Chen WJ, Feng D, Jia YH, Xie LX. Four serum microRNAs identified as diagnostic biomarkers of sepsis. J Trauma Acute Care Surg. 2012;73:850-854.

36. Wang JF, Yu ML, Yu G, et al. Serum miR-146a and miR-223 as potential new biomarkers for sepsis. Biochem Biophys Res Commun. 2010;394:184-188.

37. van der Heide V, Möhnle P, Rink J, Briegel J, Kreth S. Downregulation of microRNA-31 in CD4+ T cells contributes to immunosuppression in human sepsis by promoting TH2 skewing. Anesthesiology. 2016;124:908-922.

38. Möhnle P, Schütz SV, van der Heide V, et al. MicroRNA-146a controls Th1-cell differentiation of human CD4+ T lymphocytes by targeting PRKCE. Eur J Immunol. 2015;45:260-272.

39. Zhou J, Chaudhry H, Zhong Y, et al. Dysregulation in microRNA expression in peripheral blood mononuclear cells of sepsis patients is associated with immunopathology. Cytokine. 2015;71:89-100.

40. Roderburg C, Luedde M, Vargas Cardenas D, et al. Circulating microRNA-150 serum levels predict survival in patients with critical illness and sepsis. PLoS One. 2013;8:e54612.

41. Tacke F, Roderburg C, Benz F, et al. Levels of circulating miR133a are elevated in sepsis and predict mortality in critically ill patients. Crit Care Med. 2014;42:1096-1104.

42. Wang L, Wang HC, Chen C, et al. Differential expression of plasma miR-146a in sepsis patients compared with non-sepsisSIRS patients. Exp Ther Med. 2013;5:1101-1104.

43. Ma Y, Vilanova D, Atalar K, et al. Genome-wide sequencing of cellular microRNAs identifies a combinatorial expression signature diagnostic of sepsis. PLoS One. 2013;8:e75918.

44. Han Y, Dai QC, Shen HL, Zhang XW. Diagnostic value of elevated serum miRNA-143 levels in sepsis. J Int Med Res. 2016;44:875-881

45. Kingsley SMK, Bhat BV. Role of microRNAs in sepsis. Inflamm Res. 2017;66:553-569.

46. Neudecker V, Brodsky KS, Kreth S, Ginde AA, Eltzschig HK. Emerging roles for microRNAs in perioperative medicine. Anesthesiology. 2016;124:489-506.

47. Yamagishi M, Nakano K, Miyake A, et al. Polycomb-mediated loss of miR-31 activates NIK-dependent NF- $\mathrm{KB}$ pathway in adult T cell leukemia and other cancers. Cancer Cell. 2012;21:121-135.

48. Liu CJ, Tsai MM, Hung PS, et al. miR-31 ablates expression of the HIF regulatory factor FIH to activate the HIF pathway in head and neck carcinoma. Cancer Res. 2010;70:1635-1644.

49. Wang $X$, Wang $X$, Liu $X$, et al. miR-15a/16 are upregulated in the serum of neonatal sepsis patients and inhibit the LPS-induced inflammatory pathway. Int J Clin Exp Med. 2015;8:5683-5690.

50. Li T, Morgan MJ, Choksi S, Zhang Y, Kim YS, Liu ZG. MicroRNAs modulate the noncanonical transcription factor NF-kappaB pathway by regulating expression of the kinase IKKalpha during macrophage differentiation. Nat Immunol. 2010;11:799-805.
51. Sheedy FJ, Palsson-McDermott E, Hennessy EJ, et al. Negative regulation of TLR4 via targeting of the proinflammatory tumor suppressor PDCD4 by the microRNA miR-21. Nat Immunol. 2010;11:141-147.

52. Lu TX, Munitz A, Rothenberg ME. MicroRNA-21 is up-regulated in allergic airway inflammation and regulates IL-12p35 expression. J Immunol. 2009;182:4994-5002.

53. Yu S, Zhang R, Zhu C, Cheng J, Wang H, Wu J. MicroRNA-143 downregulates interleukin-13 receptor alpha1 in human mast cells. Int J Mol Sci. 2013;14:16958-16969.

54. Wong JJ, Au AY, Gao D, et al. RBM3 regulates temperature sensitive miR-142-5p and miR-143 (thermomiRs), which target immune genes and control fever. Nucleic Acids Res. 2016;44:2888-2897.

55. Pham H, Rodriguez CE, Donald GW, et al. miR-143 decreases COX-2 mRNA stability and expression in pancreatic cancer cells. Biochem Biophys Res Commun. 2013;439:6-11.

56. Yang L, Boldin MP, Yu Y, et al. miR-146a controls the resolution of T cell responses in mice. J Exp Med. 2012;209:1655-1670.

57. Li Y, Su J, Li F, Chen X, Zhang G. MiR-150 regulates human keratinocyte proliferation in hypoxic conditions through targeting HIF- $1 \alpha$ and VEGFA: Implications for psoriasis treatment. PLoS One. 2017;12:e175459.

58. Sang W, Wang Y, Zhang C, et al. MiR-150 impairs inflammatory cytokine production by targeting ARRB-2 after blocking CD28/ B7 costimulatory pathway. Immunol Lett. 2016;172:1-10.

59. Ceppi M, Pereira PM, Dunand-Sauthier I, et al. MicroRNA-155 modulates the interleukin-1 signaling pathway in activated human monocyte-derived dendritic cells. Proc Natl Acad Sci U S A. 2009;106:2735-2740.

60. Yao R, Ma YL, Liang W, et al. MicroRNA-155 modulates Treg and Th17 cells differentiation and Th17 cell function by targeting SOCS1. PLoS One. 2012;7:e46082.

61. Pedersen IM, Otero D, Kao E, et al. Onco-miR-155 targets SHIP1 to promote TNFalpha-dependent growth of B cell lymphomas. EMBO Mol Med. 2009;1:288-295.

62. Aziz F. The emerging role of miR-223 as novel potential diagnostic and therapeutic target for inflammatory disorders. Cell Immunol. 2016;303:1-6.

63. Bauernfeind F, Rieger A, Schildberg FA, Knolle PA, Schmid-Burgk JL, Hornung V. NLRP3 inflammasome activity is negatively controlled by miR-223. J Immunol. 2012;189:4175-4181.

64. Lawrence T, Fong C. The resolution of inflammation: antiinflammatory roles for NF-kappaB. Int J Biochem Cell Biol. 2010;42:519-523.

65. Hayden MS, West AP, Ghosh S. NF-kappaB and the immune response. Oncogene. 2006;25:6758-6780.

66. Seok J, Warren HS, Cuenca AG, et al; Inflammation and Host Response to Injury, Large Scale Collaborative Research Program. Genomic responses in mouse models poorly mimic human inflammatory diseases. Proc Natl Acad Sci U S A. 2013;110:3507-3512.

67. Podshivalova K, Salomon DR. MicroRNA regulation of T-lymphocyte immunity: modulation of molecular networks responsible for T-cell activation, differentiation, and development. Crit Rev Immunol. 2013;33:435-476.

68. Johnson ER, Matthay MA. Acute lung injury: epidemiology, pathogenesis, and treatment. J Aerosol Med Pulm Drug Deliv. 2010;23:243-252.

69. Yang K, Gao B, Wei W, et al. Changed profile of microRNAs in acute lung injury induced by cardio-pulmonary bypass and its mechanism involved with SIRT1. Int J Clin Exp Pathol. 2015;8:1104-1115.

70. Rajasekaran S, Pattarayan D, Rajaguru P, Sudhakar Gandhi PS, Thimmulappa RK. MicroRNA regulation of acute lung injury and acute respiratory distress syndrome. J Cell Physiol. 2016;231:2097-2106.

71. Guo Z, Wen Z, Qin A, et al. Antisense oligonucleotide treatment enhances the recovery of acute lung injury through IL-10secreting M2-like macrophage-induced expansion of CD4+ regulatory T cells. J Immunol. 2013;190:4337-4348.

72. Rao R, Nagarkatti P, Nagarkatti M. Role of miRNA in the regulation of inflammatory genes in staphylococcal enterotoxin 
B-induced acute inflammatory lung injury and mortality. Toxicol Sci. 2015;144:284-297.

73. Zeng Z, Gong H, Li Y, et al. Upregulation of miR-146a contributes to the suppression of inflammatory responses in LPSinduced acute lung injury. Exp Lung Res. 2013;39:275-282.

74. Vergadi E, Vaporidi K, Theodorakis EE, et al. Akt2 deficiency protects from acute lung injury via alternative macrophage activation and miR-146a induction in mice. J Immunol. 2014;192:394-406.

75. Guo Z, Gu Y, Wang C, et al. Enforced expression of miR$125 \mathrm{~b}$ attenuates LPS-induced acute lung injury. Immunol Lett. 2014;162:18-26.

76. Starkey Lewis PJ, Dear J, Platt V, et al. Circulating microRNAs as potential markers of human drug-induced liver injury. Hepatology. 2011;54:1767-1776.

77. Starkey Lewis PJ, Merz M, Couttet P, et al. Serum microRNA biomarkers for drug-induced liver injury. Clin Pharmacol Ther. 2012;92:291-293.

78. Yamada H, Suzuki K, Ichino N, et al. Associations between circulating microRNAs (miR-21, miR-34a, miR-122 and miR-451) and non-alcoholic fatty liver. Clin Chim Acta. 2013;424:99-103.

79. Bala S, Tilahun $\mathrm{Y}$, Taha $\mathrm{O}$, et al. Increased microRNA-155 expression in the serum and peripheral monocytes in chronic HCV infection. J Transl Med. 2012;10:151.

80. Press AT, Traeger A, Pietsch C, et al. Cell type-specific delivery of short interfering RNAs by dye-functionalised theranostic nanoparticles. Nat Commun. 2014;5:5565.

81. Neudecker V, Haneklaus M, Jensen O, et al. Myeloid-derived miR-223 regulates intestinal inflammation via repression of the NLRP3 inflammasome. J Exp Med. 2017;214:1737-1752.

82. Polytarchou C, Oikonomopoulos A, Mahurkar S, et al. Assessment of circulating microRNAs for the diagnosis and disease activity evaluation in patients with ulcerative colitis by using the nanostring technology. Inflamm Bowel Dis. 2015;21:2533-2539.

83. Fan PC, Chen CC, Chen YC, Chang YS, Chu PH. MicroRNAs in acute kidney injury. Hum Genomics. 2016;10:29.

84. Du J, Cao X, Zou L, et al. MicroRNA-21 and risk of severe acute kidney injury and poor outcomes after adult cardiac surgery. PLoS One. 2013;8:e63390.

85. Gaede L, Liebetrau C, Blumenstein J, et al. Plasma microRNA-21 for the early prediction of acute kidney injury in patients undergoing major cardiac surgery. Nephrol Dial Transplant. 2016;31:760-766.

86. Hu H, Jiang W, Xi X, Zou C, Ye Z. MicroRNA-21 attenuates renal ischemia reperfusion injury via targeting caspase signaling in mice. Am J Nephrol. 2014;40:215-223.

87. Jia P, Teng J, Zou J, et al. Xenon protects against septic acute kidney injury via miR-21 target signaling pathway. Crit Care Med. 2015;43:e250-e259.

88. Aguado-Fraile E, Ramos E, Conde E, et al. A pilot study identifying a set of microRNAs as precise diagnostic biomarkers of acute kidney injury. PLoS One. 2015;10:e0127175.

89. Vegter EL, van der Meer P, de Windt LJ, Pinto YM, Voors AA. MicroRNAs in heart failure: from biomarker to target for therapy. Eur J Heart Fail. 2016;18:457-468.

90. Schulte C, Karakas M, Zeller T. microRNAs in cardiovascular disease-clinical application. Clin Chem Lab Med. 2017;55:687-704.

91. D'Alessandra Y, Devanna P, Limana F, et al. Circulating microRNAs are new and sensitive biomarkers of myocardial infarction. Eur Heart J. 2010;31:2765-2773.

92. Zile MR, Mehurg SM, Arroyo JE, Stroud RE, DeSantis SM, Spinale FG. Relationship between the temporal profile of plasma microRNA and left ventricular remodeling in patients after myocardial infarction. Circ Cardiovasc Genet. 2011;4:614-619.

93. Wang GK, Zhu JQ, Zhang JT, et al. Circulating microRNA: a novel potential biomarker for early diagnosis of acute myocardial infarction in humans. Eur Heart J. 2010;31:659-666.

94. Li C, Fang Z, Jiang T, et al. Serum microRNAs profile from genome-wide serves as a fingerprint for diagnosis of acute myocardial infarction and angina pectoris. BMC Med Genomics. 2013;6:16.
95. Zampetaki A, Willeit P, Tilling L, et al. Prospective study on circulating microRNAs and risk of myocardial infarction. J Am Coll Cardiol. 2012;60:290-299.

96. Schulte C, Molz S, Appelbaum S, et al. miRNA-197 and miRNA-223 predict cardiovascular death in a cohort of patients with symptomatic coronary artery disease. PLoS One. 2015;10:e0145930.

97. Vogel B, Keller A, Frese KS, et al. Multivariate miRNA signatures as biomarkers for non-ischaemic systolic heart failure. Eur Heart J. 2013;34:2812-2822.

98. Cakmak HA, Coskunpinar E, Ikitimur B, et al. The prognostic value of circulating microRNAs in heart failure: preliminary results from a genome-wide expression study. J Cardiovasc Med (Hagerstown). 2015;16:431-437.

99. Bosnjak ZJ, Logan S, Liu Y, Bai X. Recent insights into molecular mechanisms of propofol-induced developmental neurotoxicity: implications for the protective strategies. Anesth Analg. 2016;123:1286-1296.

100. Song Q, Ma YL, Song JQ, et al. Sevoflurane induces neurotoxicity in young mice through FAS/FASL signaling. Genet Mol Res. 2015;14:18059-18068.

101. Aydin M, Deveci U. Pathophysiology of ketamine neurotoxicity. In: Preedy VR, ed. Neuropathology of Drug Addictions and Substance Misuse. London, UK: Elsevier, 2016:563-572.

102. Twaroski D, Bosnjak ZJ, Bai X. MicroRNAs: new players in anesthetic-induced developmental neurotoxicity. Pharm Anal Acta. 2015;6:357.

103. Goto G, Hori Y, Ishikawa M, Tanaka S, Sakamoto A. Changes in the gene expression levels of microRNAs in the rat hippocampus by sevoflurane and propofol anesthesia. Mol Med Rep. 2014;9:1715-1722.

104. Twaroski DM, Yan Y, Olson JM, Bosnjak ZJ, Bai X. Downregulation of microRNA-21 is involved in the propofolinduced neurotoxicity observed in human stem cell-derived neurons. Anesthesiology. 2014;121:786-800.

105. Sun W, Pei L. microRNA expression profiling of propofoltreated developing rat hippocampal astrocytes. DNA Cell Biol. 2015;34:511-523.

106. Yan $\mathrm{H}, \mathrm{Xu} \mathrm{T}$, Zhao $\mathrm{H}$, Lee KC, Wang HY, Zhang Y. Isoflurane increases neuronal cell death vulnerability by downregulating miR-214. PLoS One. 2013;8:e55276.

107. Luo T, Yin S, Shi R, et al. miRNA expression profile and involvement of Let-7d-APP in aged rats with isofluraneinduced learning and memory impairment. PLoS One. 2015;10:e0119336.

108. Jiang XL, Du BX, Chen J, Liu L, Shao WB, Song J. MicroRNA34 a negatively regulates anesthesia-induced hippocampal apoptosis and memory impairment through FGFR1. Int J Clin Exp Pathol. 2014;7:6760-6767.

109. Huang C, Zhang X, Zheng J, Chen C, Chen Y, Yi J. Upregulation of miR-137 protects anesthesia-induced hippocampal neurodegeneration. Int J Clin Exp Pathol. 2014;7:5000-5007.

110. Bolkier Y, Nevo-Caspi Y, Salem Y, Vardi A, Mishali D, Paret G. Micro-RNA-208a, $-208 b$, and -499 as biomarkers for myocardial damage after cardiac surgery in children. Pediatr Crit Care Med. 2016;17:e193-e197.

111. Yao Y, Du J, Cao X, et al. Plasma levels of microRNA-499 provide an early indication of perioperative myocardial infarction in coronary artery bypass graft patients. PLoS One. 2014;9:e104618.

112. Phillips CJ. Health economic and quality of life considerations in the management of pain. Drugs. 2003;63:43-46.

113. Andersen HH, Duroux M, Gazerani P. MicroRNAs as modulators and biomarkers of inflammatory and neuropathic pain conditions. Neurobiol Dis. 2014;71:159-168.

114. Bai G, Ambalavanar R, Wei D, Dessem D. Downregulation of selective microRNAs in trigeminal ganglion neurons following inflammatory muscle pain. Mol Pain. 2007;3:15.

115. von Schack D, Agostino MJ, Stuart Murray B, et al. Dynamic changes in the microRNA expression profile reveal multiple regulatory mechanisms in the spinal nerve ligation model of neuropathic pain. PLoS One. 2011;6:e17670.

116. Ho Kim S, Kim SH, Chung JM. An experimental model for peripheral neuropathy produced by segmental spinal nerve ligation in the rat. Pain. 1992;50:355-363. 
117. Komori N, Takemori N, Kim HK, et al. Proteomics study of neuropathic and nonneuropathic dorsal root ganglia: altered protein regulation following segmental spinal nerve ligation injury. Physiol Genomics. 2007;29:215-230.

118. Costigan M, Befort K, Karchewski L, et al. Replicate high-density rat genome oligonucleotide microarrays reveal hundreds of regulated genes in the dorsal root ganglion after peripheral nerve injury. BMC Neurosci. 2002;3:16.

119. Zhao J, Lee MC, Momin A, et al. Small RNAs control sodium channel expression, nociceptor excitability, and pain thresholds. J Neurosci. 2010;30:10860-10871.

120. Gold MS, Gebhart GF. Nociceptor sensitization in pain pathogenesis. Nat Med. 2010;16:1248-1257.

121. Basbaum AI, Bautista DM, Scherrer G, Julius D. Cellular and molecular mechanisms of pain. Cell. 2009;139:267-284.

122. Ni J, Gao Y, Gong S, Guo S, Hisamitsu T, Jiang X. Regulation of $\mu$-opioid type 1 receptors by microRNA134 in dorsal root ganglion neurons following peripheral inflammation. Eur J Pain. 2013;17:313-323.

123. Bali KK, Hackenberg M, Lubin A, Kuner R, Devor M. Sources of individual variability: miRNAs that predispose to neuropathic pain identified using genome-wide sequencing. Mol Pain. 2014;10:22.

124. Lehmann SM, Krüger C, Park B, et al. An unconventional role for miRNA: let-7 activates Toll-like receptor 7 and causes neurodegeneration. Nat Neurosci. 2012;15:827-835.

125. Park CK, Xu ZZ, Berta T, et al. Extracellular microRNAs activate nociceptor neurons to elicit pain via TLR7 and TRPA1. Neuron. 2014;82:47-54.

126. Orlova IA, Alexander GM, Qureshi RA, et al. MicroRNA modulation in complex regional pain syndrome. J Transl Med. 2011;9:195.

127. Pohl K-W, Yeol J-F, Ongl W-Y. MicroRNA changes in the mouse prefrontal cortex after inflammatory pain. Eur J Pain. 2011;15:801.e1-801.e12.

128. Imai S, Saeki M, Yanase M, et al. Change in microRNAs associated with neuronal adaptive responses in the nucleus accumbens under neuropathic pain. J Neurosci. 2011;31:15294-15299.

129. Luchting B, Heyn J, Hinske LC, Azad SC. Expression of miRNA-124a in CD4 cells reflects response to a multidisciplinary treatment program in patients with chronic low back pain. Spine (Phila Pa 1976). 2017;42:E226-E233.

130. Kappel A, Keller A. miRNA assays in the clinical laboratory: workflow, detection technologies and automation aspects. Clin Chem Lab Med. 2017;55:636-647.
131. Chen C, Ridzon DA, Broomer AJ, et al. Real-time quantification of microRNAs by stem-loop RT-PCR. Nucleic Acids Res. 2005;33:e179.

132. Benes V, Castoldi M. Expression profiling of microRNA using real-time quantitative PCR, how to use it and what is available. Methods. 2010;50:244-249.

133. Hunt EA, Broyles D, Head T, Deo SK. MicroRNA detection: current technology and research strategies. Annu Rev Anal Chem (Palo Alto Calif). 2015;8:217-237.

134. Gao L, Jiang F. MicroRNA (miRNA) profiling. In: Grützmann R, Pilarsky C, eds. Cancer Gene Profiling. Methods in Molecular Biology. New York, NY: Springer, 2016:151-161.

135. Yin JQ, Zhao RC, Morris KV. Profiling microRNA expression with microarrays. Trends Biotechnol. 2008;26:70-76.

136. Berezikov E, Cuppen E. MicroRNA discovery and expression profiling using next-generation sequencing. In: Janitz M. Next Generation Genome Sequencing. Berlin, Germany: Wiley-VCH Verlag GmbH \& Co. KGaA, 2008:217-228.

137. Hafner M, Landgraf $\mathrm{P}$, Ludwig $\mathrm{J}$, et al. Identification of microRNAs and other small regulatory RNAs using cDNA library sequencing. Methods. 2008;44:3-12.

138. MarianiS, Minunni M.Surface plasmon resonance applications in clinical analysis. Anal Bioanal Chem. 2014;406:2303-2323.

139. Ho HP, Loo FC, Wu SY, Gu D, Yong KT, Kong SK. MicroRNA biosensing with two-dimensional surface plasmon resonance imaging. Methods Mol Biol. 2017;1571:117-127.

140. Ledderose C, Heyn J, Limbeck E, Kreth S. Selection of reliable reference genes for quantitative real-time PCR in human T cells and neutrophils. BMC Res Notes. 2011;4:427.

141. Zhu W, Yang L, Shan H, et al. MicroRNA expression analysis: clinical advantage of propranolol reveals key microRNAs in myocardial infarction. PLoS One. 2011;6:e14736.

142. Izzotti A, Pulliero A. The effects of environmental chemical carcinogens on the microRNA machinery. Int J Hyg Environ Health. 2014;217:601-627.

143. Rupaimoole R, Slack FJ. MicroRNA therapeutics: towards a new era for the management of cancer and other diseases. Nat Rev Drug Discov. 2017;16:203-222.

144. Tutar L, Tutar E, Özgür A, Tutar Y. Therapeutic targeting of microRNAs in cancer: future perspectives. Drug Dev Res. 2015;76:382-388.

145. Janssen HL, Reesink HW, Lawitz EJ, et al. Treatment of HCV infection by targeting microRNA. N Engl J Med. 2013;368: $1685-1694$. 